\title{
Interspecific Aggressions between Crested Porcupines and Roe Deer
}

\author{
Lorenzo Lazzeri ${ }^{1}$ (D), Caterina Senini ${ }^{2}$ and Emiliano Mori ${ }^{1, *(\mathbb{C}}$ \\ 1 Research Unit in Behavioural Ecology and Wildlife Management, Department of Life Sciences, University of \\ Siena, Via P.A. Mattioli 4, 53100 Siena, Italy; lazzerilorenzo12@gmail.com \\ 2 Department of Veterinary Medicine Sciences, University of Bologna, Via Tolara di Sopra, 43, \\ 40064 Ozzano dell’Emilia (Bologna), Italy; caterina.senini@gmail.com \\ * Correspondence: moriemiliano@tiscali.it; Tel.: +39-333-1820342
}

Received: 9 March 2020; Accepted: 3 April 2020; Published: 4 April 2020

check for updates

Simple Summary: Behavioral interspecific interference species is well-documented only amongst carnivore mammals, whereas being rare for ungulates and rodents. We report data on interactions between roe deer and crested porcupine at feeding sites. Aggressions by crested porcupines toward roe deer, often through chasing and more rarely through biting and attacking, were noted in about $16 \%$ of observations. In the remaining $84 \%$ of observations, roe deer and porcupines feed within the same feeding site, without interacting. Aggressions occurred mostly in warm months, when interspecific competition for food between these species is suggested to be the highest.

\begin{abstract}
Despite being common amongst carnivore mammals, behavioral interference between wild herbivore species is poorly documented. Particularly, in temperate areas, where the ungulate guild is composed of a few species, and large-sized rodents are scarce, most cases of interspecific interactions involve at least one alien species. In this work, we report the first data on behavioral interactions between roe deer, Capreolus capreolus, and crested porcupine, Hystrix cristata. Aggressions by crested porcupines toward roe deer were observed in 34 out of 202 observations of both species feeding at the same site. In the other 168 observations, roe deer and porcupines shared the same feeding area, without any interaction. In $58 \%$ cases of interaction, porcupines chased and pushed roe deer away from feeding areas, and in several other cases, roe deer were bitten, or injured with quills. Aggressions by porcupines occurred mostly during warm months, when roe deer are mostly solitary and when competition for food between these species is suggested to be the highest, and against single female individuals.
\end{abstract}

Keywords: aggressions; behavioral interference; feeding sites; Capreolus capreolus; Hystrix cristata; open areas

\section{Introduction}

Interspecific and intraspecific interactions are particularly attractive for wildlife photographers and watchers [1-5], as they are often spectacular and, thus, easy to detect by non-specialists [6,7]. Behavioral interference is a form of interspecific interaction which may occur through direct physical aggression and/or resource depletion by the upper competitor toward the lower one [8-11]. Large-sized or gregarious species may outcompete small-sized or solitary ones for feeding sites [12,13]. Interspecific aggressive behavior is common for carnivores [14,15], whereas it is less documented for herbivores $[16,17]$. Amongst herbivore species, most interspecific aggressive interactions in temperate areas occur when at least one of the interacting species is alien [16-18]. Therefore, redefinition of 
species-distribution range due to human-mediated introductions and climatic change may provoke new interspecific encounters.

For instance, the roe deer, Capreolus capreolus, is the most widespread and abundant native cervid species in Europe. In detail, in Italy, this species is recorded throughout the Alps and along the Apennine ridge, up to the southernmost peninsular regions, and its range is increasing $[7,19]$. The crested porcupine, Hystrix cristata, is the largest rodent in Italy [19], living in a number of habitat types, from woodlands to rural environments and to suburban areas [20,21]. Genetics [22], paleontology [23], reproductive phenology [24], behavioral ecology [25] and ectoparasitology [26] strongly suggest a North African origin of the Italian population of this species, which may have occurred after the Fall of the Western Roman Empire (but see also [27,28] for skull morphometrics). The crested porcupine may have evolved in the Pleistocene African savannah, where the ungulate guild was very rich in species [29-31]. During the last 50 years, this species has undergone a remarkable population increase and range expansion in Italy [32].

The diet of the crested porcupines in Central Italy depends on seasonal availability of trophic resources [21]. In cold months, porcupines mainly feed on underground vegetal organs (bulbs, tubers and roots), whereas a preference for stems, fruits and epigeal plant parts is shown during spring and summer $[21,33,34]$. Therefore, in warm months, porcupines may compete for food with native ungulates feeding in open areas, e.g., the roe deer, also in Italy [35-37]. The defense strategies by the crested porcupine toward potential predators and competitors include four displays, characterized by increasing aggressiveness [38,39]: (i) dorsal quill and crest erection (which is sufficient for over $50 \%$ of interactions); (ii) tail rattling through rattle quills; (iii) hind-foot stamping and growling; and (iv) backyard/sideways attack. Most times, predators desist, remaining uninjured, but they may also be wounded to death $[38,39]$. The same behavior may be displayed by crested porcupines toward conspecifics in captivity [40] or potential competitors, e.g., for food. This is particularly evident in warm months and at the start of autumn, i.e., when porcupines feed on epigeal parts of plants and on fruits [21,33].

The aim of this work was to describe interspecific interactions occurring between roe deer and crested porcupines at feeding sites (i.e., fallows and ecotones). We expected that most direct interactions would occur in warm months (spring and summer), i.e., when diet overlap amongst these species is likely to be the highest $[33,37]$.

\section{Materials and Methods}

Field data on interactions between roe deer and crested porcupines in open areas (fallows and ecotones) were collected directly by 48 qualified selective hunters involved in roe deer culling from huts and turrets, as well as through the help of the local Hunting Agency (ATC Gr6). We asked hunters to collect data throughout the year, between 2015 and 2020, in 18 sites of Northern-Central Italy (provinces of Grosseto, Siena, Arezzo, La Spezia and Genoa). In this area, roe deer culling occurs between the 1st of October and the 15th of March. However, monitoring of roe deer occurrence is carried out by cullers throughout the year; consistently, observations (anecdotal data) occurred throughout the four seasons. In Tuscany, selective ungulate culling requires that interested hunters attend a 48-hour course to learn how to distinguish between ungulate species (roe deer, fallow deer (Dama dama), red deer (Cervus elaphus), mouflon (Ovis aries) and wild boar), as well as individual sex and age. Observations were carried out from vantage points located at least at 150-300 $\mathrm{m}$ of distance, always at dusk or dawn. Between 2018 and 2020, we filled a dataset including all the observations reported by asking notes to hunters: incomplete records (i.e., those lacking date or other information were not included in our analyses. Photographic data $(n=2)$ were also provided by other national mammal experts (A. Pastorino and A. Pieragnoli).

We filled a dataset with the following information: (1) location and date of observations; (2) season; (3) number of individuals of crested porcupines and roe deer; (4) roe deer sex and age (adult, i.e., $\geq 2$ years old, or juveniles $\leq 2$ years old, following body size, [7]); and (5) description of the interaction. 
Porcupines are sexually monomorphic: therefore, it was not possible to determine their sex without a direct manipulation [41]. We kept only records including all the required information; unluckily, it was not possible to obtain reliable data to distinguish between fawns and yearlings amongst juvenile roe deer.

We used a generalized linear model, using a dataset with all observations indicating presence or absence of interspecific aggression (i.e., binomial regression model). We tested if the occurrence of an aggressive interaction between the roe deer and the crested porcupine was affected by season, cold months (October-March) vs. warm months (April-September), and by roe deer age (adult or juvenile) and sex (male or female). We ran the model through the R software (version 3.5.1., R Foundation for Statistical Computing, Wien, Austria).

\section{Results}

A total of 202 observations (94 in cold months, 108 in warm ones) with crested porcupines and roe deer (90 males, 102 females; 96 adults, 106 juveniles), feeding at a distance of 5-30 meters, were carried out at 18 sites located in Northern-Central Italy (total hours of observation $=171$ ). Only 34 ( $16.8 \%$ cases) involved interspecific interactions between roe deer and crested porcupine, with the latter species always resulting in being dominant (Table S1 in Supplementary File).

Most of the interactions (58.6\%) were represented by chasing of crested porcupines toward one or two roe deer, whereas $31.0 \%$ involved roe deer getting injured with quills (resulting in five death cases) and $10.4 \%$ being bitten (Figure 1).

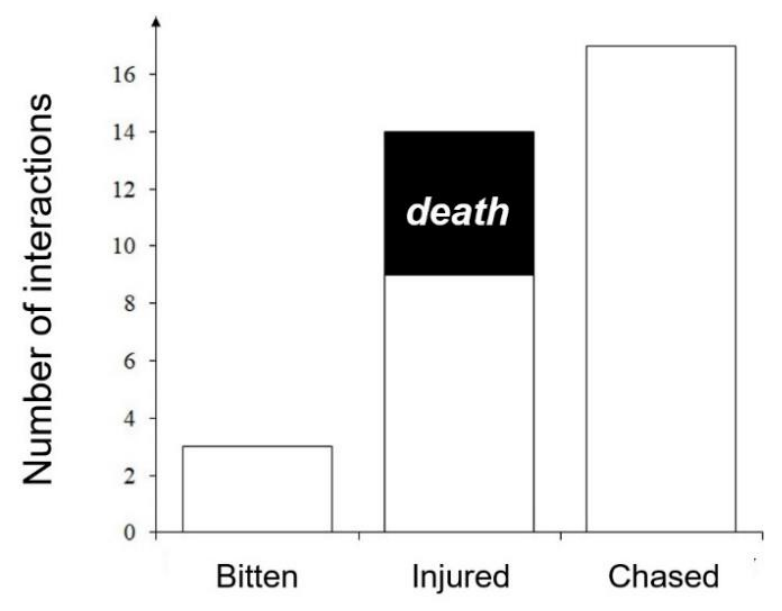

Effect of porcupine attack on roe deer

Figure 1. Aggressive interactions between crested porcupine and roe deer.

Aggressions were more likely to occur during the warm months (warm-cold months: $1.02 \pm 0.13$, $z=8.22, p<0.001$ ), against females (females-males: $3.84 \pm 0.51, z=10.02, p<0.001$ ) and juvenile roe deer (juvenile-adult: $3.35 \pm 0.64, z=9.45, p<0.001$ ).

\section{Discussion}

In this study, we reported, for the first time, some patterns of direct aggressive interactions between a large rodent and a cervid, i.e., the roe deer. Porcupines become particularly intolerant toward other species and conspecifics in cold months, i.e., at the peak of their reproductive period, both in feeding areas and in the surroundings of their burrows [42-44]. In cold months, harassments by crested porcupines (quill/crest erection) have been observed against wild boar, Sus scrofa, in feeding areas, and, in a few cases, wild boars have been wounded by porcupine quills (e.g., in Alta Val d'Elsa, A. Pieragnoli, personal communication 2020, [38]). Porcupines tend to avoid areas characterized by 
high densities of wild boar, particularly where rooting disturbance is high [42,45]. Furthermore, winter is the only period in which porcupines avoid den sharing with other species [43]. This may represent a sort of "defense" strategy toward feeding resources and offspring protection from potential predators and competitors $[24,38,43,44]$.

Surprisingly, attacks by crested porcupines never occurred in cold months, i.e., when the roe deer mostly live in groups [46], and when most of the diet of the crested porcupine is composed by underground storage organs, which may limit interspecific competition [21,33,34]. In warm months, movements of the crested porcupines in Italy strongly increase, to reach open areas, where most food items consumed in these seasons occur [33,47-49]. In spring and summer, roe deer, particularly single females with juveniles, are quite widespread in open areas, which may enhance the potential for behavioral interference [50,51]. This is in line with observations on interference between fallow deer and roe deer, which increases in warm months, when open areas are attractive for both species $[11,13,17]$. In warm months, porcupines also use open areas for feeding, when cultivations provide this large rodent with clumped and abundant food [47-49]. In this context, encounters with female and juvenile roe deer may thus increase, thus creating the context for behavioral interactions. Accordingly, most physical attacks involving bites or injuries occurred toward females or young individuals, the latter having little or no experience. In general, aggressions require energy loss, which may explain why porcupines attacked roe deer only rarely [52], as already observed for fallow and roe deer [13]. Conversely, roe deer never displaced crested porcupine from feeding sites, despite being heavier.

The collection of opportunistic and haphazard data is subject to many unknown patterns, due to how records arise. Particularly, our work involved woodland species active at night, when human sighting ability is the lowest. We cannot rule out that some other interactions may have occurred between roe deer and crested porcupine, without being recorded. Furthermore, information on recording efforts and biases cannot be evaluated when data are not collected through standardized protocols; thus, the use of citizen science should be circumscribed to a few kinds of scientific works, such as large-scale surveys or preliminary studies $[53,54]$.

\section{Conclusions}

In an evolutionary timescale, we suggest that competition and predation pressure may have led crested porcupines living in open habitats in Africa to develop a quill armor and to feed mostly on underground storage organs, to limit competition with native grazer herbivores [31,55]. Where niche overlap increases, crested porcupines start to defend resources even through direct attacks $[38,43,55]$, and this may happen both at den sites and at feeding sites, particularly where the crested porcupine may be an introduced species, e.g., in Italy. Despite being rare, aggressions of roe deer by crested porcupine occur mostly in the warm months and toward young individuals, which may be the most prone to approach porcupines. Amongst mammals, ungulates and rodents represent the main herbivore groups at temperate latitudes. Therefore, interspecific interactions can be predicted, even with effects on rodent populations [56-58]. Up until now, most studies on rodent-ungulate interactions have been conducted on small rodents, with very few studies involving large ones [42,45]. Large-sized rodents would require a higher food amount with respect to small-sized ones, thus enhancing the potential for competition with other herbivores. Future studies on interactions between ungulate and rodent species should be carried out to focus on both exploitation and interference mechanisms of competition.

Supplementary Materials: The following are available online at http://www.mdpi.com/2076-2615/10/4/623/s1, Table S1: Aggressive interactions between crested porcupine and roe deer in open areas.

Author Contributions: Conceptualization: L.L., C.S. and E.M.; supervision: E.M.; field survey and data collection: C.S. and L.L.; data analysis: L.L. and E.M.; manuscript writing, review and editing: L.L., C.S. and E.M. All authors have read and agreed to the published version of the manuscript.

Funding: This research was not funded by any institution.

Acknowledgments: We thank Sandro Lovari and Francesco Ferretti for encouragement and all hunters for providing us with data. Alessio Pieragnoli and Alberto Pastorino provided us with useful data and 
recommendations. Two anonymous reviewers and, particularly, Maria Vittoria Mazzamuto greatly improved our first draft with their comments.

Conflicts of Interest: The authors declare no conflict of interest.

\section{References}

1. Ballantyne, R.; Packer, J.; Hughes, K. Tourists' support for conservation messages and sustainable management practices in wildlife tourism experiences. Tour. Manag. 2009, 30, 658-664. [CrossRef]

2. Dickinson, J.L.; Zuckerberg, B.; Bonter, D.N. Citizen science as an ecological research tool: Challenges and benefits. Annu. Rev. Ecol. Evol. Syst. 2010, 41, 149-172. [CrossRef]

3. Bik, H.M.; Goldstein, M.C. An introduction to social media for scientists. PLoS Biol. 2013, 11, e1001535. [CrossRef] [PubMed]

4. Tiago, P.; Pereira, H.M.; Capinha, C. Using citizen science data to estimate climatic niches and species distributions. Basic Appl. Ecol. 2017, 20, 75-85. [CrossRef]

5. Nelson, X.J.; Fijn, N. The use of visual media as a tool for investigating animal behaviour. Anim. Behav. 2013, 85, 525-536. [CrossRef]

6. Dylewski, Ł.; Mikula, P.; Tryjanowski, P.; Morelli, F.; Yosef, R. Social media and scientific research are complementary-YouTube and shrikes as a case study. Sci. Nat. 2017, 104, 48. [CrossRef] [PubMed]

7. Mori, E.; Di Bari, P.; Coraglia, M. Interference between roe deer and Northern chamois in the Italian Alps: Are Facebook groups effective data sources? Ethol. Ecol. Evol. 2018, 30, 277-284. [CrossRef]

8. Tilman, D. Resource Competition and Community Structure; Princeton University Press: Princeton, NJ, USA, 1982.

9. Downes, S.; Bauwens, D. An experimental demonstration of direct behavioural interference in two Mediterranean lacertid lizard species. Anim. Behav. 2002, 63, 1037-1046. [CrossRef]

10. Dame, E.A.; Petren, K. Behavioural mechanisms of invasion and displacement in Pacific island geckos (Hemidactylus). Anim. Behav. 2006, 71, 1165-1173. [CrossRef]

11. Ferretti, F.; Sforzi, A.; Lovari, S. Behavioural interference between ungulate species: Roe are not on velvet with fallow deer. Behav. Ecol. Sociobiol. 2011, 65, 875-887. [CrossRef]

12. Valeix, M.; Chamaillé-Jammes, S.; Fritz, H. Interference competition and temporal niche shifts: Elephants and herbivore communities at waterholes. Oecologia 2007, 153, 739-748. [CrossRef] [PubMed]

13. Ferretti, F. Interspecific aggression between fallow and roe deer. Ethol. Ecol. Evol. 2011, 23, 179-186. [CrossRef]

14. Palomares, F.; Caro, T.M. Interspecific killing among mammalian carnivores. Am. Nat. 1999, 153, 492-508. [CrossRef] [PubMed]

15. Donadio, E.; Buskirk, S.W. Diet, morphology and interspecific killing in Carnivora. Am. Nat. 2006, 167, 524-536. [CrossRef] [PubMed]

16. Mori, E.; Ferretti, F.; Fattorini, N. Alien war: Ectoparasite load, diet and temporal niche partitioning in a multi-species assembly of small rodents. Biol. Invasions 2019, 21, 3305-3318. [CrossRef]

17. Ferretti, F.; Mori, E. Displacement interference between wild ungulate species: Does it occur? Ethol. Ecol. Evol. 2020, 32, 2-15. [CrossRef]

18. Stokes, V.L.; Banks, P.B.; Pech, R.P. Influence of residency and social odors in interactions between competing native and alien rodents. Behav. Ecol. Sociobiol. 2012, 66, 329-338. [CrossRef]

19. Loy, A.; Aloise, G.; Ancillotto, L.; Angelici, F.M.; Bertolino, S.; Capizzi, D.; Castiglia, R.; Colangelo, P.; Contoli, L.; Cozzi, B.; et al. Mammals of Italy: An annotated checklist. Hystrix Ital. J. Mammal. 2019, 30, 87-106.

20. Mori, E.; Lovari, S.; Sforzi, A.; Romeo, G.; Pisani, C.; Massolo, A.; Fattorini, L. Patterns of spatial overlap in a monogamous large rodent, the crested porcupine. Behav. Process. 2014, 107, 112-118. [CrossRef]

21. Lovari, S.; Corsini, M.T.; Guazzini, B.; Romeo, G.; Mori, E. Suburban ecology of the crested porcupine in a heavily poached area: A global approach. Eur. J. Wildl. Res. 2017, 63, 10. [CrossRef]

22. Trucchi, E.; Facon, B.; Gratton, P.; Mori, E.; Stenseth, N.C.; Jentoft, S. Long live the alien: Is high genetic diversity a pivotal aspect of crested porcupine (Hystrix cristata) long-lasting and successful invasion? Mol. Ecol. 2016, 25, 3527-3539. [CrossRef] [PubMed]

23. Masseti, M.; Albarella, U.; De Grossi Mazzorin, J. The crested porcupine, Hystrix cristata L., 1758, in Italy. Anthropozoologica 2010, 45, 27-42. [CrossRef] 
24. Mori, E.; Menchetti, M.; Lucherini, M.; Sforzi, A.; Lovari, S. Timing of reproduction and paternal cares in the crested porcupine. Mamm. Biol. 2016, 81, 345-349. [CrossRef]

25. Mori, E.; Nourisson, D.H.; Lovari, S.; Romeo, G.; Sforzi, A. Self-defence may not be enough: Moonlight avoidance in a large, spiny rodent. J. Zool. 2014, 294, 31-40. [CrossRef]

26. Mori, E.; Sforzi, A.; Menchetti, M.; Mazza, G.; Lovari, S.; Pisanu, B. Ectoparasite load in the crested porcupine Hystrix cristata Linnaeus, 1758 in Central Italy. Parasitol. Res. 2015, 114, 2223-2229. [CrossRef]

27. Angelici, F.M.; Capizzi, D.; Amori, G.; Luiselli, L. Morphometric variation in the skulls of the crested porcupine Hystrix cristata from mainland Italy, Sicily, and northern Africa. Mamm. Biol. 2003, 68, 165-173. [CrossRef]

28. Mori, E.; Ancillotto, L.; Lovari, S.; Russo, D.; Nerva, L.; Mohamed, W.F.; Motro, Y.; Di Bari, P.; Plebani, M. Skull shape and Bergmann's rule in mammals: Hints from Old World porcupines. J. Zool. 2019, 308, 47-55. [CrossRef]

29. Kappelman, J.; Plummer, T.; Bishop, L.; Duncan, A.; Appleton, S. Bovids as indicators of Plio-Pleistocene paleoenvironments in East Africa. J. Hum. Evol. 1997, 32, 229-256. [CrossRef]

30. Steele, T.E. Vertebrate records: Late Pleistocene of Africa. In Encyclopedia of Quaternary Science; Elias, S., Ed.; Elsevier: Oxford, UK, 2007; pp. 3139-3150.

31. Werdelin, L.; Sanders, W.J. Cenozoic Mammals of Africa; California University Press: Berkeley, CA, USA, 2010.

32. Mori, E.; Sforzi, A.; Bogliani, G.; Milanesi, P. Range expansion and redefinition of a crop-raiding rodent associated with global warming and temperature increase. Clim. Chang. 2018, 150, 319-331. [CrossRef]

33. Bruno, E.; Riccardi, C. The diet of the crested porcupine Hystrix cristata L., 1758 in a Mediterranean rural area. Zeitschrift für Säugetierkunde 1995, 60, 226-236.

34. Mori, E.; Bozzi, R.; Laurenzi, A. Feeding habits of the crested porcupine Hystrix cristata L. 1758 (Mammalia, Rodentia) in a Mediterranean area of Central Italy. Eur. Zool. J. 2017, 84, 261-265. [CrossRef]

35. Mussa, P.P.; Aceto, P.; Abba, C.; Sterpone, L.; Meineri, G. Preliminary study on the feeding habits of roe deer (Capreolus capreolus) in the western Alps. J. Anim. Physiol. Anim. Nutr. 2003, 87, 105-108. [CrossRef] [PubMed]

36. Sangiuliano, A.; Lovari, S.; Ferretti, F. Dietary partitioning between European roe deer and European brown hare. Eur. J. Wildl. Res. 2016, 62, 527-535. [CrossRef]

37. Freschi, P.; Fascetti, S.; Riga, F.; Cosentino, C.; Rizzardini, G.; Musto, M. Diet composition of the Italian roe deer (Capreolus capreolus italicus) (Mammalia: Cervidae) from two protected areas. Eur. Zool. J. 2017, 84, 34-42. [CrossRef]

38. Mori, E.; Maggini, I.; Menchetti, M. When quills kill. The defence strategy of the crested porcupine Hystrix cristata L., 1758. Mammalia 2014, 78, 229-234. [CrossRef]

39. Thalgaspitiya, S.P.; Wijerathne, B.T.; Thennakoon, B.D. Close encounter with a prickly soccer ball: An injury from an Indian crested porcupine. Wilderness Environ. Med. 2018, 29, 239-242. [CrossRef] [PubMed]

40. Švara, T.; Zdovc, I.; Gombač, M.; Pogačnik, M. Quill injury-cause of death in a captive Indian crested porcupine (Hystrix indica, Kerr, 1792). Maced. Vet. Rev. 2015, 38, 119-122. [CrossRef]

41. Mori, E.; Lovari, S. Sexual size monomorphism in the crested porcupine (Hystrix cristata). Mamm. Biol. 2014, 79, 157-160. [CrossRef]

42. Mazzamuto, M.V.; Lo Valvo, M.; Anile, S. The value of by-catch data: How species-specific surveys can serve non-target species. Eur. J. Wildl. Res. 2019, 65, 68. [CrossRef]

43. Mori, E.; Menchetti, M. Living with roommates in a shared den: Spatial and temporal segregation among semifossorial mammals. Behav. Process. 2019, 164, 48-53. [CrossRef]

44. Pigozzi, G. On agonistic interactions between female crested porcupines (Hystrix cristata). Atti della Società Italiana di Scienze Naturali, Museo Civico di Storia Naturale di Milano 1997, 137, 127-130.

45. Mori, E. Porcupines in the landscape of fear: Effects of hunting with dogs on the behaviour of a non-target species. Mammal Res. 2017, 62, 251-258. [CrossRef]

46. Hewison, A.J.M.; Vincent, J.P.; Reby, D. Social organization of European roe deer. In The European Roe Deer: The Biology of Success; Anderson, R., Duncan, P., Linnell, J.D.C., Eds.; Scandinavian University Press: Stockholm, Sweden, 1998; pp. 189-220.

47. Laurenzi, A.; Bodino, N.; Mori, E. Much ado about nothing: Assessing the impact of a problematic rodent on agriculture and native trees. Mammal Res. 2016, 61, 65-72. [CrossRef] 
48. Ettiss, K.; Chammen, M.; Khorchani, T. Food preferences of the crested porcupine Hystrix cristata L., 1758 (Rodentia: Hystricidae) in South-Eastern Tunisia. Acta Zool. Bulgarica 2020, 72, 37-42.

49. Pigozzi, G.; Patterson, I.J. Movements and diet of crested porcupines in the Maremma Natural Park, central Italy. Acta Theriologica 1990, 35, 173-180. [CrossRef]

50. Pellerin, M.; Calenge, C.; Said, S.; Gaillard, J.M.; Fritz, H.; Duncan, P.; Van Laere, G. Habitat use by female western roe deer (Capreolus capreolus): Influence of resource availability on habitat selection in two contrasting years. Can. J. Zool. 2010, 88, 1052-1062. [CrossRef]

51. San José, C.; Lovari, S. Ranging movements of female roe deer: Do home-loving does roam to mate? Ethology 1998, 104, 721-728. [CrossRef]

52. Georgiev, A.V.; Klimczuk, A.C.; Traficonte, D.M.; Maestripieri, D. When violence pays: A cost-benefit analysis of aggressive behavior in animals and humans. Evol. Psychol. 2013, 11, 147470491301100313. [CrossRef]

53. Silvertown, J. A new dawn for citizen science. Trends Ecol. Evol. 2009, 24, 467-471. [CrossRef]

54. Bonney, R.; Shirk, J.L.; Phillips, T.B.; Wiggins, A.; Ballard, H.L.; Miller-Rushing, A.J.; Parrish, J.K. Next steps for citizen science. Science 2014, 343, 1436-1437. [CrossRef]

55. Kerbis Peterhans, J.C.; Celesia, G.G.; Gnoske, T.P. Lion-porcupine interactions in Africa, including impacts on lion predatory behaviour. J. East Afr. Nat. Hist. 2019, 108, 1-15. [CrossRef]

56. Focardi, S.; Capizzi, D.; Monetti, D. Competition for acorns among wild boar (Sus scrofa) and small mammals in a Mediterranean woodland. J. Zool. 2000, 250, 329-334. [CrossRef]

57. Fagiani, S.; Fipaldini, D.; Santarelli, L.; Burrascano, S.; Del Vico, E.; Giarrizzo, E.; Mei, M.; Vigna-Taglianti, A.; Boitani, L.; Mortelliti, A. Monitoring protocols for the evaluation of the impact of wild boar (Sus scrofa) rooting on plants and animal in forest ecosystems. Hystrix Ital. J. Mammal. 2014, 25, 31-38.

58. Foster, C.N.; Barton, P.S.; Lindenmayer, D.B. Effects of large native herbivores on other animals. J. Appl. Ecol. 2014, 51, 929-938. [CrossRef]

(C) 2020 by the authors. Licensee MDPI, Basel, Switzerland. This article is an open access article distributed under the terms and conditions of the Creative Commons Attribution (CC BY) license (http://creativecommons.org/licenses/by/4.0/). 